\title{
Brassinosteroid Signal Transduction: A Mix of Conservation and Novelty
}

\author{
Peng Peng and Jianming $\mathrm{Li}^{*}$
}

Department of Molecular, Cellular, and Developmental Biology, University of Michigan, Ann Arbor, Michigan 48109, USA

\begin{abstract}
Brassinosteroids (BRs) are a unique class of plant steroids that are structurally similar to animal steroid hormones and play important roles in plant growth and development. Unlike the animal steroids, which bind to classical intracellular steroid receptors that directly modulate gene activities after translocation into the nucleus, the plant steroids rely on transmembrane receptor kinases to activate a phosphorylation cascade to regulate gene expression. Recent genetic and biochemical studies have identified several critical BR signaling components and revealed a striking mechanistic similarity between the plant steroid signaling pathway and several well-studied animal signaling cascades involving a receptor kinase and glycogen synthase
\end{abstract}

kinase 3 (GSK3). A working model for BR signal transduction proposes that BR initiates its signaling pathway by promoting heterodimerization of two transmembrane receptor-like kinases at the cell surface, leading to inhibition of a GSK3 kinase and subsequent stabilization and nuclear accumulation of two GSK3 substrates that regulate BR-responsive genes. Such a simple model provides a framework for continued investigation of molecular mechanism(s) of plant steroid signaling.

Key words: Arabidopsis; Brassinosteroid; GSK3; Leucine-rich-repeat receptor-like kinase; Receptor heterodimerization; Steroid signaling

\section{INTRODUCTION}

Brassinosteroids (BRs) are a unique class of plant polyhydroxysteroids that are structurally similar to the well-studied animal and insect steroids. When applied exogenously to plants, BRs affect a variety of physiological processes, including cell division, cell elongation, vascular differentiation, root growth inhibition, biotic and abiotic stress tolerance, reproductive development, and modulation of gene

Received: 9 May 2003; accepted: 7 August 2003; Online publication: 18 December 2003

*Corresponding author; e-mail: jian@umich.edu

expression (Clouse and Sasse 1998). The essential function of endogenous BRs was revealed by dramatic morphological changes of mutants that are defective in BR biosynthesis in several plant species including Arabidopsis, pea, rice, and tomato (Hong and others 2002; Mori and others 2002; Fujioka and Yokota 2003). In Arabidopsis, BR-deficient mutants display a characteristic mutant phenotype, including a dwarf stature with dark green and rounded rosette leaves, delayed flowering and senescence, reduced apical dominance and male fertility, altered vascular structure and cytoskeleton organization, and abnormal skotomorphogenesis in the dark ( $\mathrm{Li}$ and others 1996; Szekeres and others 1996). All of 
these growth defects can be suppressed by supplying BRs to the growth medium.

In animals, steroid hormone signaling is initiated mainly by intracellular steroid receptors that belong to a large family of structurally related nuclear receptors with a characteristic three-domain structure consisting of an $\mathrm{N}$-terminal transcriptional activation domain, a middle DNA-binding domain, and a C-terminal ligand-binding/protein dimerization domain (Aranda and Pascual 2001). In the absence of steroids, these intracellular steroid receptors are locked into nonproductive forms by association with heat shock proteins and other chaperones. Upon steroid binding, the receptors dissociate from the heat shock protein complexes, move into the nucleus, and bind to regulatory DNA sequences of their target genes to either activate or repress gene expression, leading to various physiological and developmental changes. Alternatively, animal steroid signaling can be rapidly activated at the cell surface by the membrane-localized steroid receptors to induce the so-called "nongenomic" steroid effects on cell physiology independent of gene regulation (Losel and Wehling 2003). Candidates for such membrane steroid receptors include the membrane-associated classical steroid receptors (Shaul 2002), G-protein coupled receptors (GPCRs, Grazzini and others 1998), and a novel family of membrane steroid-binding proteins that are structurally similar to GPCRs (Hammes 2003). It is known that calcium, CAMP, heterotrimeric G proteins, and protein phosphorylation are involved in the membrane-initiated steroid signaling pathways (Cato and others 2002).

By contrast, plants seem to lack the classical steroid signaling pathway, and the completely sequenced Arabidopsis genome does not encode any protein that shows significant sequence homology to the highly conserved nuclear steroid receptors (Arabidopsis Genome Initiative 2000). Instead, plant steroids are mainly, if not exclusively, recognized by cell surface receptors to initiate their signaling pathways to regulate a variety of physiological processes ( $\mathrm{Li}$ 2003). Recent advances in the study of BR signaling have dramatically increased our understanding of how the plant steroid signal is perceived on the cell surface, transmitted into the cytosol, and finally transduced into the nucleus to regulate gene activities (Clouse 2002a, 2002b). This review highlights the characterization of several Arabidopsis proteins that are believed to be involved in plant steroid perception and signal transduction. Biochemical and genetic studies of these BR signaling components are beginning to reveal the mode of steroid action in plants.

\section{BRI1: A CRITICAl Component of a Membrane BR RECEPTOR}

BRIl (Brassinosteroid-Insensitive $\underline{1}$ ), the first known component of the plant steroid signaling pathway, was initially discovered in a genetic screen for Arabidopsis mutants that showed normal root growth in the presence of high concentrations of BR (Clouse and others 1996). Repeated genetic screens for loss-of-function BR-insensitive mutants only resulted in the identification of additional bril alleles, indicating that BRIl is an essential nonredundant component of the plant steroid signaling pathway (Kauschmann and others 1996; Li and Chory 1997; Noguchi and others 1999; Friedrichsen and others 2000). bril mutants are morphologically indistinguishable from BR-deficient dwarf mutants but cannot be rescued by exogenous BR application (Kauschmann and others 1996; Li and Chory 1997). Interestingly, these mutants also accumulate high levels of brassinolide (BL), the most active BR, and its biosynthetic precursors, with the more severe bril mutants accumulating higher levels of endogenous BRs, suggesting that BRIl plays an important role in regulating BR homeostasis (Noguchi and others 1999). It was reported that BR insensitivity in bril mutants was also observed at the molecular level (Kauschmann and others 1996). The BR-induced expression of two xyloglucan endotransglycosylase genes, TCH4 and meri5, was absent in bril-2 mutants, although the GA-induced meri5 expression was still observed. Taken together, these genetic and physiological studies strongly suggest that BRII encodes an essential component of the plant steroid signaling pathway.

The BRIl gene was cloned by a map-based strategy and was found to encode a leucine-rich-repeat receptor-like kinase (LRR-RLK) that consists of an LRR-containing extracellular domain, a single transmembrane segment, and a cytoplasmic Ser/Thr kinase domain (Figure 1) (Li and Chory 1997). The extracellular domain is composed of several discrete regions, including an $\mathrm{N}$-terminal signal peptide, a leucine-zipper motif that might mediate proteinprotein interaction, and two pairs of cysteine residues flanking 25 tandem LRRs that are disrupted by a 70 amino acid (70AA) island domain between the 21 st and 22nd LRRs (Figure 1). Analyses of various bril mutant alleles identified several regions essential for in vivo BRIl function (Figure 1) (Li and Chory 1997; Noguchi and others 1999; Friedrichsen and others 2000). The bril-5 mutant contains a Cys69Tyr substitution in the first cysteine pair that might be important for mediating disulfide-linked dimerization of BRIl with itself or its action part- 


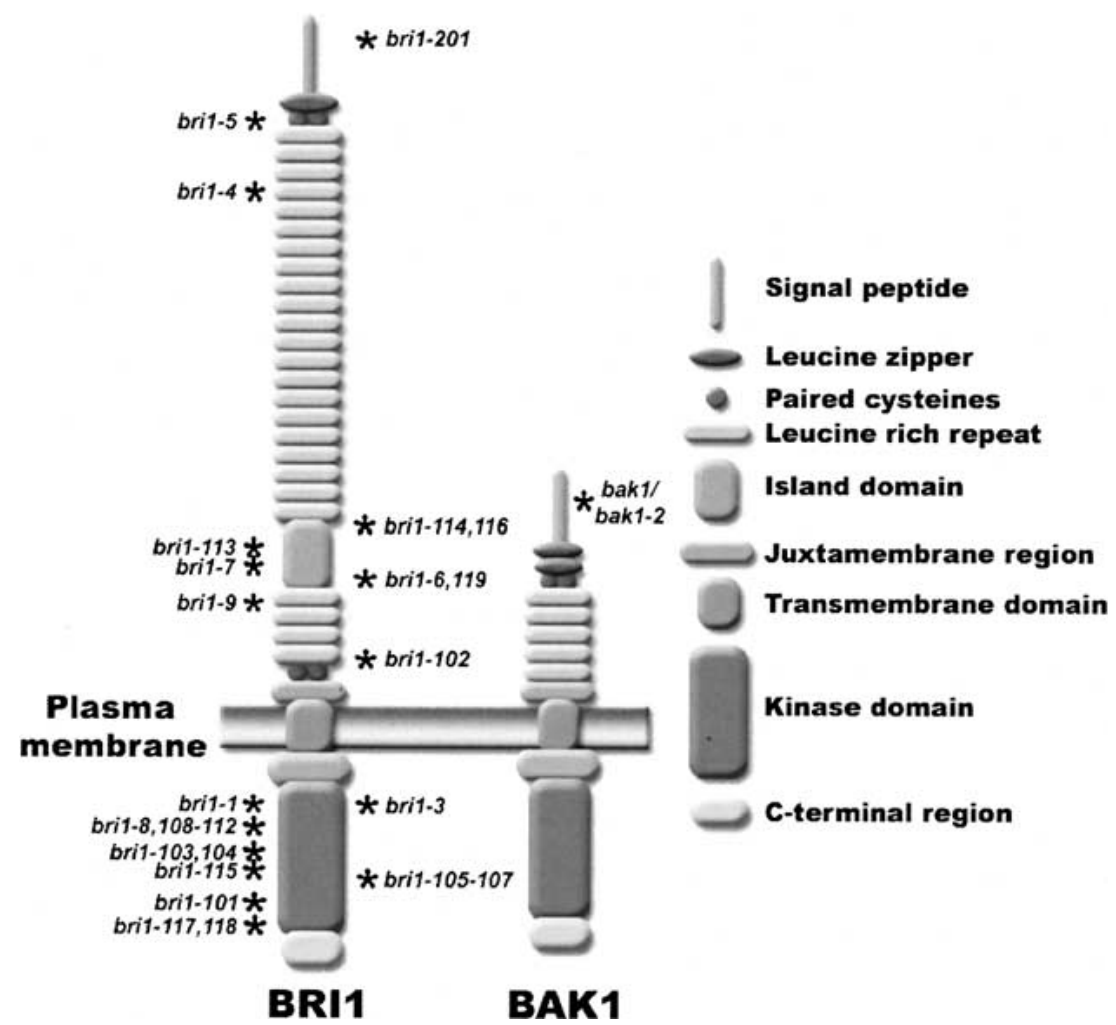

Figure 1. Schematic structure of BRII and BAKl receptor kinases. Both receptor kinases are made up of similar structural domains and sequence motifs, but BAKl is a much smaller protein, containing only 5 LRRs and missing the 70AA island domain and the second cysteine pair. Asterisks represent known mutations found in BRIl and BAKl.

ners, while the bril-9 mutant harbors a Ser662Phe missense mutation in the 22nd LRR that is immediately downstream from the 70AA island. The bril102 mutation changes Thr750 to Ile, which is located between the last LRR and the second cysteine pair. Five mutations were identified in the 70AA island domain, including two nonsense (bri1-114 and bri1-116) and three missense mutations (bri1-6/ bril-119, bri1-7, and bril-113), each involving a change of a glycine residue. The clustering of mutations in this domain led to a hypothesis that the 70AA island might be directly or indirectly involved in binding the plant steroids. As expected from its similarity with animal RLKs, allele sequencing also confirmed the essential role of the kinase domain for transmitting BR signals. Among 28 bril alleles sequenced to date, 15 alleles contain mutations in the kinase domain (Li and Chory 1997; Noguchi and others 1999; Friedrichsen and others 2000). These kinase mutations might affect receptor dimerization, recruitment of downstream signaling proteins, or the catalytic activity of the kinase domain, thus blocking the propagation of BR signaling.

The deduced BRIl protein sequence predicts that BRIl spans across the cell membrane. Although there is no immunohistochemical data to prove this prediction and to determine the topology of the
BRIl protein, confocal microscopic analysis of a BRII:GFP fusion protein revealed that BRIl is localized at the plasma membrane (Friedrichsen and others 2000). The BRIl cytoplasmic domain is expected to contain serine/threonine kinase activity that is essential for transmitting BR signal into the cytosol. Biochemical analyses of an E. coli-expressed calmodulin-binding peptide (CBP)-BRIl kinase fusion protein and a C-terminal HA-tagged full-length BRIl protein expressed in human cell cultures confirmed that BRIl is indeed a functional kinase in vitro (Friedrichsen and others 2000; Oh and others 2000). Phosphoamino acid analyses revealed that the in vitro autophosphorylated BRIl protein contains both phospho-Ser and phospho-Thr but no phospho-Tyr (Friedrichsen and others 2000; Oh and others 2000), thus proving that BRIl belongs to the serine/threonine kinase family. Matrix-assisted laser desorption/ionization-mass spectrometry analyses with an in vitro phosphorylated CBP-BRII kinase fusion protein identified at least 12 autophosphorylation sites, including 5 in the juxtamembrane segment, 5 in the core kinase domain, and 2 in the carboxyl terminal region ( $\mathrm{Oh}$ and others 2000). These phosphorylated residues may participate in regulating the kinase activity of the BRIl protein or serve as docking sites to recruit different downstream BR signaling proteins into an activated 
$\mathrm{BR}$ receptor complex. Thus, BRIl is a membraneassociated receptor kinase that plays a key role in BR signaling through Ser/Thr phosphorylation.

The importance of BRIl in BR signaling was further supported by the molecular genetic characterization of BR-insensitive dwarf mutants in other plant species. Two allelic rice dwarf mutants with erect leaves, d61-1 and d61-2, were found to be less sensitive to BR treatment and accumulated higherthan-wild-type levels of BRs. Molecular cloning experiments revealed that a Thr989Ile mutation in the kinase domain and a Val491 Met mutation in the 18th LRR of a rice BRIl homologue were responsible for the BR-insensitive dwarf phenotype of the d61-1 and d61-2 mutants, respectively (Yamamuro and others 2000). In pea, three BR-related dwarf mutants were known (Nomura and others 1997, 1999; Schultz and others 2001), including two BRdeficient mutants, $l k$ and $l k b$, and a BR-insensitive mutant, lka. It was reported that the $l k a$ mutant, which is morphologically similar to $l k$ and $l k b$ mutants but could not be rescued by exogenous BR treatment, contains a missense mutation in a pea BRIl homologue (Normura and others 2001). Similarly, two BR-insensitive tomato mutants, curl3 (Koka and others 2000) and absl (Montoya and others 2002), were recently found to contain a nonsense mutation and a missense mutation in the extracellular domain and the kinase domain, respectively, of a tomato BRIl homologue, tBRIl (Montoya and others 2002). Surprisingly, tBRIl was found to be identical to SR160, a putative membrane receptor for a peptide hormone systemin involved in wounding response (Scheer and Ryan 2002), suggesting that tBRIl might be able to recognize two distinct ligands: a steroid and a peptide (Szekeres 2003).

Although there is no direct demonstration that purified BRIl proteins can bind BL or its active analogues, several lines of experimental evidence support that BRIl is crucial for a membrane BR receptor activity. He and others (2000) provided indirect evidence showing that BRIl's extracellular domain is involved in BR sensing. The extracellular domain, the transmembrane $\alpha$-helix, plus a small intracellular juxtamembrane segment of the BRII protein were fused to the cytoplasmic kinase domain of Xa21, a rice LRR-RLK involved in disease resistance (Song and others 1995), to generate a BRIl:Xa21 chimeric receptor. Upon treatment with $\mathrm{BL}$, this chimeric receptor can initiate a typical plant defense response in rice cell cultures, including rapid cell death, oxidative burst, and the expression of pathogenesis-related genes. Both the BRIl portion and the Xa21 kinase domain are necessary for the activity of the BRIl:Xa2l chimeric receptor because a mutation in either domain completely abolished the BR-activated defense responses. These results clearly demonstrated the essential role of BRIl's extracellular domain, especially the 70AA island, for BR binding. Further support for BRIl being a membrane BR receptor came from several BR-binding assays. Wang and others (2001) showed that transgenic Arabidopsis plants overexpressing BRIl exhibited a higher BR sensitivity and contained a higher BR binding activity in their membrane fractions. Consistent with previous genetic data, mutations in the extracellular domain eliminated such a BR binding activity, whereas mutations in the kinase domain had no effect on BR binding. Importantly, such a BR binding activity can be coimmunoprecipitated with BRIl. In line with the hypothesis that BRIl is a crucial element of a BR receptor, BL treatment stimulated BRIl autophosphorylation in wild-type Arabidopsis seedlings but not in bril mutants containing a kinase-dead mutation. Based on these data, it was suggested that BR binding, either directly or indirectly, to the extracellular domain of BRIl, would activate the intrinsic kinase activity of BRIl to propagate the plant steroid signaling.

\section{BAK1: A BRI1-INTERACTING RECEPTOR KINASE}

It is well known that animal receptor kinases are activated by ligand-induced homo- or heterodimerization. Thus, it would be reasonable to assume that BRIl is activated in a similar fashion by BR via the formation of homo- or heterodimers. The latter model is much more favored by the recent discovery of BRIl-associated receptor kinase 1 (BAKl) as a potential coreceptor for BRIl (Li and others 2002; Nam and Li 2002).

BAKl was identified independently by a yeast two-hybrid screen as a specific BRIl-interacting protein (Nam and Li 2002) and by a gain-of-function activation-tagging screen as an extragenic suppressor of bril-5, a weak extracellular bril mutation mentioned above (Noguchi and others 1999). Like BRIl, BAKl is also an LRR-containing receptor kinase (Figure 1) and belongs to a small subfamily of the Arabidopsis LRR-RLK (LRRII, Shiu and Bleecker 2001) that contains 13 other members including the Arabidopsis SOMATIC EMBRYOGENESIS RECEPTOR kinase 1 (AtSERKl), which was known to enhance somatic embryogenesis when overexpressed (Hecht and others 2001). However, BAKl contains only 5 LRRs in its extracellular domain and 
lacks the 70AA island domain, a characteristic feature of BRIl and its homologues. Northern blot analysis revealed that BRII and BAKl share similar gene expression domains, and confocal microscopic analysis of transgenic plants expressing a BAKl:GFP fusion protein showed that BAKl is also a membrane-localized protein. Coimmunoprecipitation experiments were performed to demonstrate that BRIl and BAKl interact physically in yeast cells and in plants (Li and others 2002; Nam and Li 2002). These data strongly suggest that BAKl and BRII have the potential to form a heterodimer at the cell surface.

Genetic studies with both gain-of-function and loss-of-function approaches showed that BAKl is also involved in BR signaling ( $\mathrm{Li}$ and others 2002; Nam and Li 2002). Overexpression of the BAKl gene not only suppressed the bril-5 mutation, but also rescued, in a dose-dependent manner, the mutant phenotype of bril-301 containing a weak kinase mutation, indicating that BAKl becomes a rate-limiting factor when the activity of BRIl is reduced. In addition, BAKl overexpression in a wildtype background gave rise to a phenotype that was previously observed in transgenic Arabidopsis plants overexpressing BRII (Wang and others 2001) or DWARF4 (DWF4) that encodes a P450 steroid hydroxylase catalyzing a rate-limiting step of BR biosynthesis (Choe and others 1998, 2001). In contrast, two null bakl mutations, caused by T-DNA insertions in either the first exon or the third intron of the $B A K 1$ gene, resulted in a weak bril-like phenotype with a semidwarf stature, a compact rosette, shortened inflorescent stems, and reduced sensitivity to BR in inhibiting root elongation ( $\mathrm{Li}$ and others 2002; Nam and Li 2002). The weak phenotype of the two null bakl mutants was not surprising at all given the fact that there are 13 BAKl-like receptor kinases in Arabidopsis. Some of the BAKl homologues, especially those sharing similar expression patterns with BRIl, might also heterodimerize with BRIl to mediate BR signaling and contribute to signal specificity.

The demonstration that BAKl participates in BR signaling and that BAKl physically interacts with BRIl in plants suggests that BAKl might function as a coreceptor for BRIl in initiating BR signaling. Such a hypothesis was supported by several lines of genetic evidence. BAKl overexpression can only suppress weak bril mutations but fails to rescue the mutant phenotype of a null bril mutant or a bril-5 det 2 double mutant with the second mutation affecting BR biosynthesis ( $\mathrm{Li}$ and others 2002), indicating that the BR signaling activity of BAK1 depends on a (at least partially) functional BRll and the presence of the plant steroids. In addition, a null bakl mutation could enhance a weak bril mutation but apparently had no significant effect on a null bril mutation (Nam and Li 2002). Furthermore, overexpression of a kinase-dead BAKl in the weak bril-5 mutant led to a more severe dwarf morphology (Li and others 2002), most likely due to dominant-negative effect of the mutated BAKl on the formation of the presumed signaling-active BRIl/BAKl dimers.

Although the genetic studies concluded that BRIl and BAKl could function together as a heterodimer in mediating plant steroid signaling, biochemical analyses of the interaction between the two receptor kinases led to two different heterodimerization models to explain how they are activated in response to BR binding. One model closely resembles the receptor tyrosine kinase model in which ligand binding would trigger receptor dimerization to activate its intrinsic kinase activity through transphosphorylation, thus initiating a phosphorylation cascade (Schlessinger 2000). The other is modeled after the TGF $\beta$ receptor, which is composed of a homodimeric type I TGF $\beta$ receptor and a homodimeric type II TGF $\beta$ receptor. TGF $\beta$ binding to the type II receptor promotes the formation of a heterotetramer to allow the constitutively active type II receptor to phosphorylate and activate the type I receptor, leading to propagation of the TGF $\beta$ signal (Attisano and Wrana 2002).

Nam and Li (2002) hypothesized that BRIl and BAK I exist mainly as inactive monomers that are in equilibrium with a small pool of active heterodimer. BR binding promotes the formation of the BRIl/ BAKl heterodimer, resulting in activation of both receptor kinases through transphosphorylation and initiation of a phosphorylation-mediated BR signaling cascade. Such a model, similar to the receptor tyrosine kinase model, is based on the biochemical studies of the two receptor kinases expressed in yeast cells as full-length proteins. Both BRIl and BAKl were inactive when they were expressed alone but became activated when they were coexpressed and interacted with each other. However, neither BRIl nor BAKl was phosphorylated when one of them was inactivated by site-directed mutagenesis, which had no effect on their physical interaction. Because yeast cells do not produce bioactive BRs, these phosphorylation assays indicated that the dimerization between BRIl and BAKl is sufficient to activate the two interacting receptor kinases but their activation requires transphosphorylation by their partners. Consistent with the hypothesis that a BR-binding protein is needed for BR to bind a BRIl-containing steroid 
receptor (Li and Chory 1997), BR treatment of yeast cells coexpressing BRIl and BAKl did not increase the phosphorylation levels of the two receptor kinases or enhance their physical interaction (Nam and Li 2002). On the other hand, BR treatment was known to stimulate BRIl autophosphorylation in plants. Additional genetic and biochemical studies will determine whether BR activates the BRIl kinase activity by triggering the dimerization of BRIl/ BAKl in plants and whether the BRIl/BAKl dimerization is sufficient to activate downstream BR signaling events.

Li and others (2002) proposed that BRII/BAKl interaction is more similar to the interaction between the type I and type II TGF $\beta$ receptors, based on the biochemical studies of the recombinant cytoplasmic domains of the two receptor kinases expressed in E. coli. Unlike the yeast-expressed fulllength proteins, the E. coli-expressed BRIl or BAKl fusion protein was an active kinase when tested individually by in vitro autophosphorylation assays. Interestingly, the phosphorylation level of BAKl was significantly increased when it was mixed with BRIl; however, no BRIl-stimulated BAKl phosphorylation was observed if BAKl was inactivated, suggesting that the increased BAKl phosphorylation was likely a result of BAKl autophosphorylation after it was stimulated by BRIl. On the contrary, the phosphorylation level of BRIl remained the same regardless of whether it was incubated with an active or an inactive BAKl. These results suggested a unidirectional phosphorylation model in which an activated BRIl phosphorylates and activates BAKl to initiate a BR signaling cascade. The main difference between this model and the TGF $\beta$ receptor model is that BRII has to be activated first by the plant steroid, whereas the type II TGF $\beta$ receptor is a constitutively active kinase. Although BR treatment did increase the autophosphorylation level of BRIl in plants, one has to propose a different dimerization model, such as BRIl homodimerization, or a completely new mechanism to explain how BRIl itself is activated in response to BRs.

\section{Protein Coligands for BR TO BIND ITS RECEPTOR?}

Although the 70AA island in the extracellular domain of BRIl is critical for BR binding, such a domain is surrounded by LRR motifs that are best known for mediating protein/protein interactions. This suggests that a protein coligand might be needed to help the plant steroid to interact with the
70AA island (Li and Chory 1997). The Arabidopsis genome encodes several proteins that are highly similar to animal sex steroid binding proteins, which are thought to mediate membrane-initiated steroid signaling (Rosner and others 1999). A recent structural study also implicated a steroid carrier function for Bet v l (Markovic-Housley and others 2003), a major birch pollen allergen that belongs to a large family of pathogenesis-related plant proteins (PR-10). Bet v l was found to contain a large Yshaped hydrophobic cavity that can accommodate two molecules of deoxycholate and display a specific noncovalent interaction with BL. Arabidopsis contains at least 40 proteins sharing the conserved Bet $\mathrm{v}$ l structural domain, and some of them could function as protein coligands for BL to bind to its receptors. The involvement of putative BR-binding proteins in BR perception was further supported by the discovery of BRS1, a putative serine carboxypeptidase, in a genetic screen for extragenic suppressors of bril-5 (Li and others 200la). BRSI overexpression suppressed only the extracellular bril mutation but had no effect on a bril kinase mutation. In addition, the phenotypic suppression of bril-5 by BRSI overexpression required the presence of active BR. Thus, BRSI most likely functions before the activation of a BR receptor, possibly by converting an inactive precursor of a putative BR-binding protein to its active form, which can then facilitate the binding of BR to the BRIl-containing BR receptor at the cell surface.

\section{BIN2: A Cytoplasmic Kinase Negatively Regulating BR Signaling}

Extensive genetic screens for Arabidopsis mutants showing the BR-deficient phenotype but displaying no response to BR treatment resulted in the identification of the second BRASSINOSTEROID-INSENSITIVE locus, BIN2/DWARF12 (Li and others 2001b; Choe and others 2002), which is allelic to the UCU1 gene uncovered in genetic screens for leaf development mutants (Perez-Perez and others 2002). In contrast to known bril alleles that are recessive lossof-function mutations, all known bin2/dwarf12/ucul mutants carry semidominant gain-of-function mutations, including the weakest $u c u l-3$ mutant that was previously thought to contain a recessive lossof-function mutation ( $\mathrm{Li}$ and others 2001b; Choe and others 2002; Perez-Perez and others 2002; Peng and $\mathrm{Li}$, unpublished data). Tetraploid analysis indicated that the bin2 mutant phenotype is likely caused by hypermorphic mutations that increase the production or activity of the BIN2 protein. A 

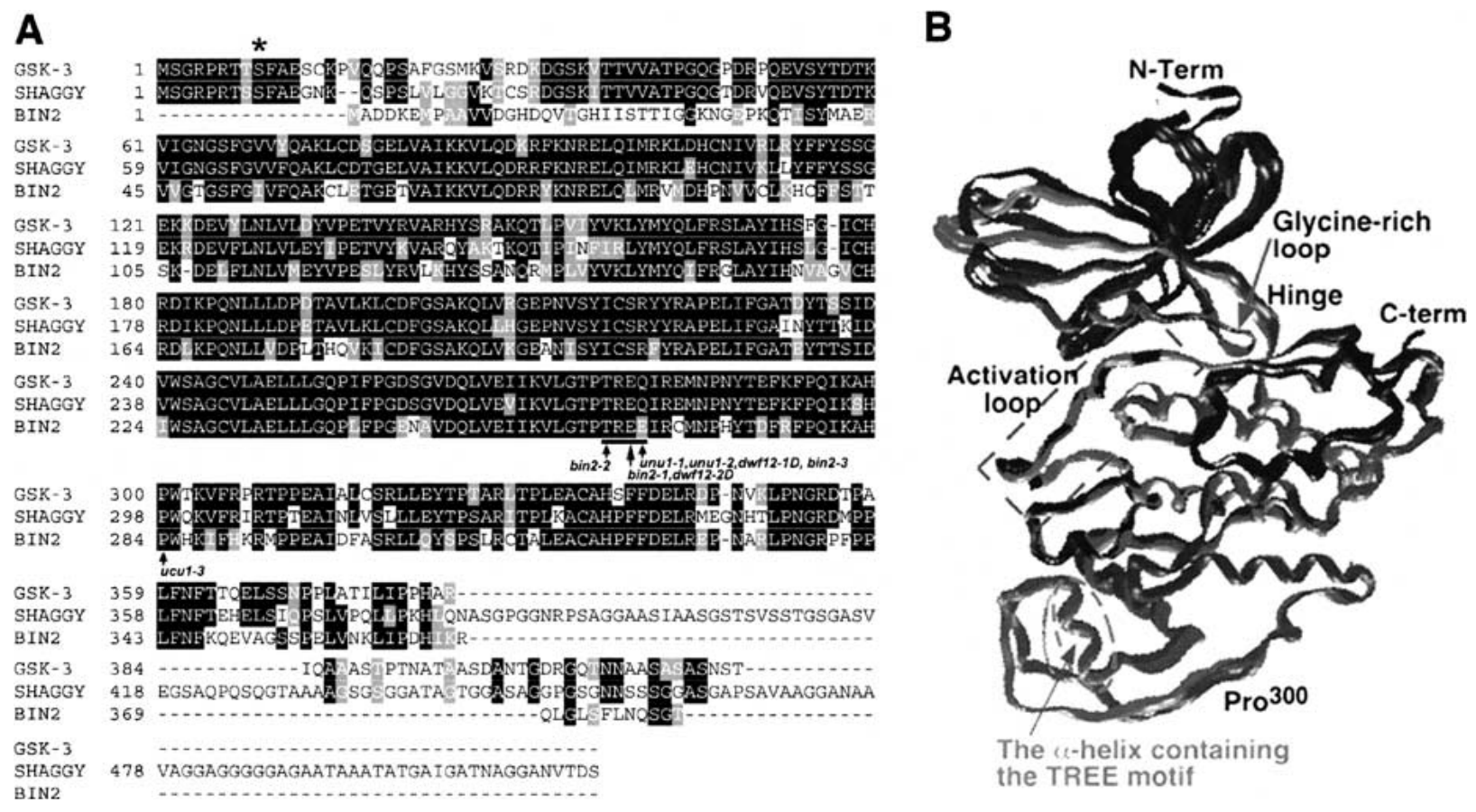

Figure 2. Sequence alignment and structural modeling of the Arabidopsis BIN2 protein. (A) Sequence comparison between BIN2 and the human GSK3 $\beta$ and Drosophila SHAGGY kinases. Black shading indicates identical amino acids, while gray shading denotes similar residues. The TREE motif in BIN2 is underlined by the black bar and the known bin2/ dwarf12/ucul mutations are indicated by arrows. The Ser9 residue in human GSK3 $\beta$, critical for regulation, is highlighted by the asterisk. (B) The modeled structure of BIN2 is superimposed onto the three known GSK3 structures in the Protein Data Bank (PDB ID: 1I09, IGNG, and 1H8F). The structure modeling was performed at the Swiss-Model automated knowledge-based protein-modeling server (http://www.expasy.org/swissmod/SWISS-MODEL.html). The locations of Nterminus, C-terminus, activation loop, glycine-rich loop, the hinge that links the $\mathrm{N}$-terminal $\beta$-strand domain with the Cterminal $\alpha$-helical domain, and the short $\alpha$-helix containing the TREE motif are indicated.

root growth inhibition assay indicated that bin2 mutants are insensitive only to BR but display a hypersensitivity to ABA and retain normal sensitivity to other plant hormones, including GA, auxin, cytokinin, and ethylene ( $\mathrm{Li}$ and others 2001b). Like bril mutants, bin2 mutants were found to accumulate a higher level of $\mathrm{BL}$ and its biosynthetic precursors (Choe and others 2002), suggesting that BIN2 also participates in regulating BR homeostasis. Taken together, these data suggest that BIN2 is an important negative regulator in the plant steroid signaling pathway.

BIN2 encodes a cytoplasmic Ser/Thr kinase that displays $70 \%$ sequence identity within the catalytic domain to those of the mammalian GSK3 and the Drosophila SHAGGY kinases (Figure 2A) (Li and Nam 2002), which play key roles as negative regulators in a wide variety of signaling processes controlling cell proliferation, cell differentiation, cytoskeleton dynamics, and programmed cell death (Frame and Cohen 2001). In the absence of extracellular signals, GSK3 is a constitutively active kinase that phosphorylates a variety of protein substrates to block signal transduction through direct inhibition of their biochemical activities, interfering with their subcellular localization, or promoting their degradation (Frame and Cohen 2001). In response to extracellular signals, GSK3 becomes inactivated, thus relieving its inhibitory effect on its downstream targets.

Consistent with the genetic results suggesting that bin2 mutants carry hypermorphic bin2 alleles, the recombinant BIN2 kinase harboring the bin2-1 mutation was more active towards a peptide substrate than the wild-type recombinant kinase (Li and Nam 2002). In addition, it was shown that overexpression of the wild-type BIN2 gene gave rise to a bril-like phenotype in transgenic plants, with a higher BIN2 expression level leading to a more severe dwarf phenotype. Furthermore, decreasing the BIN2 expression via a cosuppression strategy could suppress a weak bril phenotype. These results further supported the hypothesis that BIN2 functions as a negative regulator in BR signaling and implied that the inhibition of BIN2 kinase activity would constitute a key regulatory 

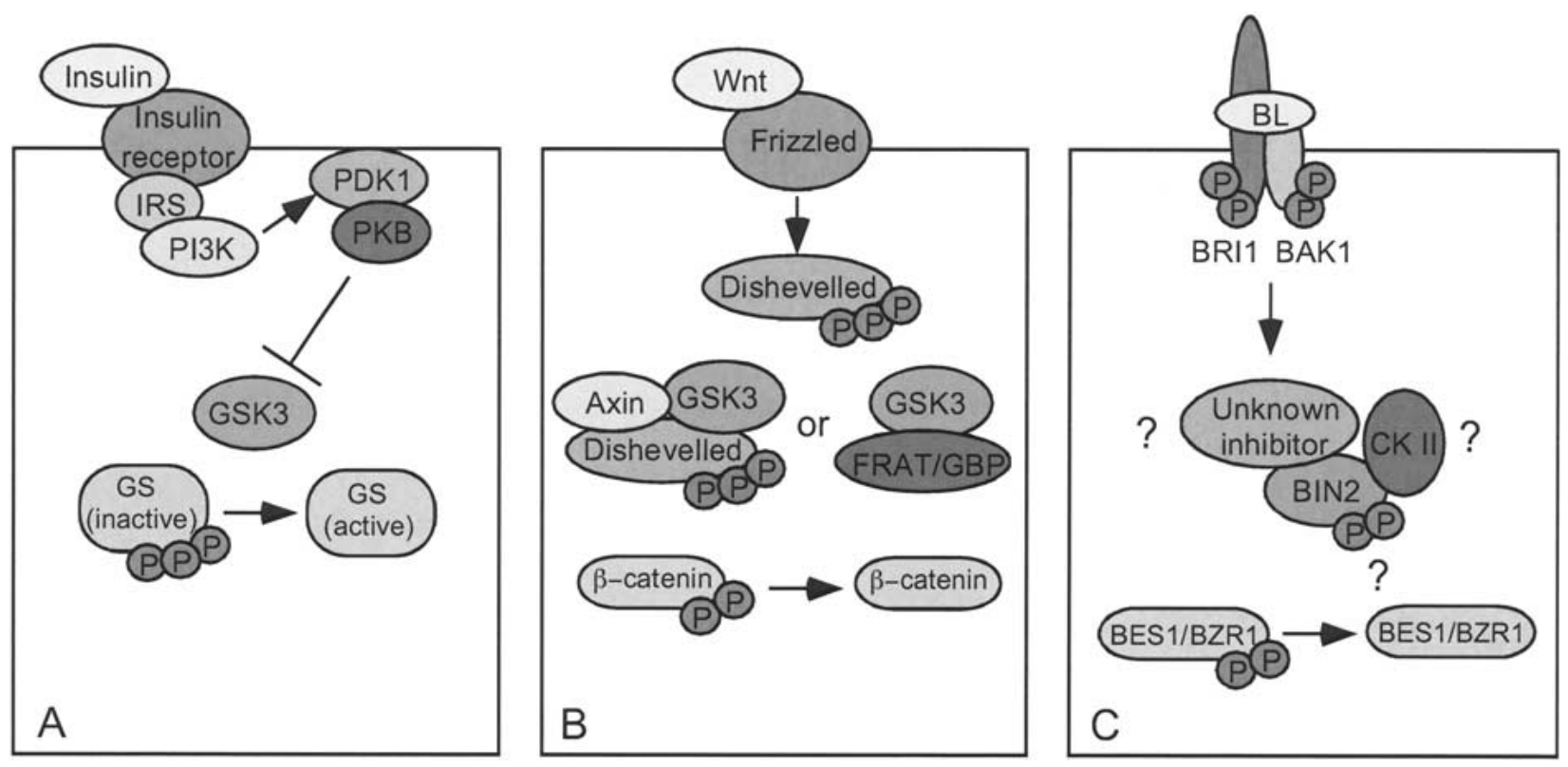

Figure 3. Regulation of GSK3 kinases in different signaling pathways. (A) The binding of insulin to its receptor initiates a phosphorylation cascade involving insulin receptor substrate (IRS), phosphoinositide-3-kinase (PI3K), and phosphoinositide-dependent kinase 1 (PDK1), which leads to the activation of protein kinase B (PKB) that can inhibit GSK3 $\beta$ by phosphorylating the Ser9 residue of the latter kinase. As a result, glycogen synthase (GS) becomes hypophosphorylated and active. (B) In the Wnt signaling, Wnt binds to its receptor, Frizzled, leading to the activation of a cytoplasmic protein, Disheveled. The activated Disheveled can directly interfere with the formation of the GSK3 $\beta /$ Axin/ $\beta$-catenin destruction complex or recruit another cytosolic protein, FRAT/GBP, which can compete with $\beta$-catenin for binding GSK3 $\beta$, thus preventing GSK3 $\beta$ from phosphorylating $\beta$-catenin. (C) A hypothetical model of BIN2 regulation in plants. In response to BR signals, both BRIl and BAKl are activated, leading to the activation of an unknown BIN2-binding protein or an alleged CKII that phosphorylates BIN2 at the suspected TREE motif, which can then inhibit the BIN2 kinase activity.

step after the plant steroids activate the BRIlcontaining BR receptor.

In animals, the GSK3 kinase is generally regulated by two different mechanisms (Figure 3A, 3B). One involves protein phosphorylation and the other depends on protein/protein interaction. In the insulin signaling pathway, insulin binding to its receptor triggers a phosphorylation cascade that eventually phosphorylates GSK3 at a serine residue near its N-terminus (Figures 2A, 3A) (Cross and others 1995). The phosphorylated serine residue binds to a conserved substrate-binding site, thus preventing GSK3 from phosphorylating its downstream targets (Dajani and others 2001; ter Haar and others 2001). In the Wingless pathway, GSK3 phosphorylation of $\beta$-catenin, a critical regulator for expression of many Wnt-responsive genes, requires the formation of a multiprotein complex that includes GSK3, $\beta$-catenin, and an adapter protein named Axin (Ikeda and others 1998). Wnt proteins transduce their signals through Disheveled proteins to inhibit the GSK3 activity by the physical displacement of the kinase from the GSK3/Axin/ $\beta$ catenin complex or the recruitment of FRAT/GBP, a
GSK3-binding protein, to prevent the GSK3/ $\beta$ catenin interaction (Dominguez and Green 2001), leading to increased accumulation of $\beta$-catenin and consequent upregulation of many proliferative genes (Figure 3B).

It remains to be determined how BIN2 is regulated by the steroid signals after the activation of both BRIl and BAK1 receptor kinases. BIN2 lacks the $\mathrm{N}$-terminal serine residue that is essential for the regulation of many animal GSK3 kinases (Figure 2A). Neither BRIl nor BAKl was able to phosphorylate BIN2 and no direct physical interaction was detected between BIN2 and these two transmembrane receptor kinases (Li and Nam 2002; Nam and $\mathrm{Li}$, unpublished results), suggesting that additional BR signaling protein(s) are necessary for BIN2 inhibition in response to BR. On the other hand, the clustering of 6 out of all known 7 bin2/dwarf12/ucul mutations in a highly conserved 4-amino-acid ThrArg-Glu-Glu (TREE) motif (Choe and others 2002; Li and Nam 2002; Perez-Perez and others 2002) suggests the involvement of protein-protein interaction and/or protein phosphorylation in BIN2 regulation (Figure $3 \mathrm{C}$ ). Based on a recently resolved 
crystal structure of the human GSK3 $\beta$ kinase, the TREE motif is part of a short $\alpha$-helix that is exposed on the surface of the protein (Figure 2B) (Dajani and others 2001; ter Haar and others 2001). Thus, it is possible that this domain is critical for the interaction between BIN2 and a yet to be identified GSK3-binding protein essential for BIN2 regulation. However, the lack of mutations at other positions within the short $\alpha$-helix favors a different inhibitory mechanism. The TREE motif is highly similar to the consensus phosphorylation motif S/TxxD/E (D, E, S, $\mathrm{T}$, and $\mathrm{x}$ stand for aspartic acid, glutamic acid, serine, threonine, and any other amino acids, respectively) of casein kinase II (CKII), which also prefers acidic residues at -2 to +5 positions relative to the phosphorylation site, with the +1 and +2 positions being the most important ones (Meggio and Pinna 2003). The mutations of the threonine and the two glutamate residues in TREE motif would prevent the phosphorylation of BIN2 by such an acidic-directed protein kinase, uncoupling the Arabidopsis GSK3 kinase from a BR-activated regulatory mechanism. We are currently investigating these two possible mechanisms for BIN2 regulation and searching for missing components that link the activation of BRIl and BAKl to the inhibition of BIN2.

\section{BES1 AND BZR1: Two NuClear Components of BR Signaling}

The discovery of the cytoplasmic kinase BIN2 provided a great opportunity for identifying additional $\mathrm{BR}$ signaling components. In the absence of BR signal, BIN2 is an active kinase that would phosphorylate downstream targets to block the further transduction of BR signaling in the cytosol. Using a yeast two-hybrid method, we have identified two novel Arabidopsis proteins (originally named BIS 1 and BIS2 for BIN2 SUBSTRATE 1 and 2, respectively), sharing $88 \%$ sequence identity with each other, as potential substrates for the BIN2 GSK3 kinase (Zhao and others 2002). Interestingly, BIS 1 and BIS2 were also discovered as bril-EMS-suppressor l (BES1) and brassinozole-resistant 1 (BZRl) in two different genetic screens for mutations that suppress a weak bril mutant (Yin and others 2002a) or resistant to brassinozole, a specific BR biosynthesis inhibitor (Wang and others 2002), respectively. In yeast, BESI and BZRI displayed specific interactions with BIN2. In addition, both proteins contain multiple copies of a conserved GSK3 phosphorylation motif (S/TxxxS/T) and were phosphorylated by BIN2 in vitro (He and others
2002; Yin and others 2002a; Zhao and others 2002), apparently through a phosphorylation mechanism distinct from those of the known animal GSK3 kinases (Zhao and others 2002; Peng and Li, unpublished results). Furthermore, the BIN2-catalyzed phosphorylation of either BESI or BZRl could be specifically inhibited by lithium (Zhao and others 2002), a known inhibitor for GSK3 kinases (Ryves and Harwood 2002). These biochemical data strongly suggest that BESI and BZRl are substrates for the BIN2 GSK3 kinase and might play a role in the plant steroid signaling.

The involvement of BESI and BZRl in BR signaling was supported by several pieces of genetic evidence. First, a Pro233Leu mutation in BES I was repeatedly identified as a suppressor for three different bril mutations (Yin and others 2002a; Zhao and others 2002), while the corresponding mutation, Pro234Leu, in BZRl was able to rescue a deetiolation phenotype of dark-grown seedlings caused by brassinazole treatment, a BR-deficient mutation, or a bril mutation (Wang and others 2002). Second, not only the mutated BESI and BZR I but also the overexpression of the wild-type BZR1 protein was capable of suppressing the bin2 mutant phenotype (He and others 2002; Zhao and others 2002). Third, the besl mutation not only suppressed the bril mutant phenotype but also gave rise to a phenotype, characterized by long and bending petioles, curly leaves, and accelerated senescence, that was previously observed in transgenic plants overproducing BR or BRIl (Choe and others 2001; Wang and others 2001), indicating that the bes 1 mutation led to a constitutive BR response, most likely through upregulation of many BR-responsive genes (Yin and others 2002a). In contrast, the Pro234Leu mutation in BZRl caused a dramatic reduction in expression of the CPD gene (Wang and others 2002), which was known to be inhibited specifically by BR treatment (Mathur and others 1998), and led to a weak dwarf phenotype in the light, suggesting a role of BZRl in regulating BR homeostasis in addition to its function in promoting cell elongation. Given the fact that both bes 1 and bzrl mutations increase protein stability and nuclear accumulation of the two proteins (Wang and others 2002; Yin and others 2002a), these genetic results demonstrate that BESI and BZRI act downstream of BRIl and BIN2 as two positive regulators of the BR signal transduction pathway with overlapping yet distinct physiological functions.

Consistent with the in vitro BIN2-BES1/BZR I phosphorylation results and the hypothesis of BRmediated BIN2 regulation, BR treatment resulted in dephosphorylation of both BESI and BZRI proteins 
in wild-type Arabidopsis seedlings, leading to enhanced protein stability and increased nuclear accumulation (He and others 2002; Yin and others 2002a). In contrast, exogenous BR application had little or no effect on the phosphorylation level or protein stability of either BES1 or BZRl in bin2 mutants, presumably containing mutated BIN2 proteins resistant to a BR-initiated inhibitory mechanism. A pharmacological study with a proteasome inhibitor indicated that the phosphorylated BZRI proteins are degraded by a proteasome-mediated process (He and others 2002). These biochemical data strongly suggest that BZRI and BESI are physiological substrates for the BIN2 GSK3 kinase and that the BIN2-catalyzed phosphorylation targets both BZRI and BESI for proteasome-mediated protein degradation. Further genetic and biochemical studies are needed to confirm that BIN2 is the bona fide kinase that phosphorylates both BESI and BZRl in the absence of BR signal.

These genetic and biochemical studies revealed a striking similarity between the plant steroid signaling pathway and the Wnt signaling cascade. In the absence of BR, BIN2 is an active kinase that would phosphorylate BESI and BZRl, leading to their degradation in the cytosol to block the transduction of BR signal into the nucleus. When the plant steroid hormone binds the BRIl-containing BR receptor, BIN2 becomes inactivated by an unknown regulatory mechanism, and the hypophosphorylated BESI and BZRI proteins move into the nucleus to regulate gene expression (Figure 4) (He and others 2002; Yin and others 2002a). Similarly, under resting conditions, GSK3 phosphorylates $\beta$ catenin, leading to its ubiquitin-mediated proteolysis (Aberle and others 1997; Hart and others 1999). In response to Wnt binding to a Frizzled receptor, GSK3 is inhibited and $\beta$-catenin accumulates in the cytosol and translocates into the nucleus to regulate gene expression by association with other transcriptional factors (Nusse 1997; Hecht and Kemler 2000). However, significant difference exists between the two pathways. First, there is no sequence similarity between BRII/BAKl and Frizzled, a seven-transmembrane $G$ protein-coupled receptor (Bhanot and others 1996), or between BESI/BZRl and $\beta$-catenin that contains 7 armadillo (ARM) repeats implicated in protein-protein interactions (Peifer and Wieschaus 1990). Second, the phosphorylation mechanism of BIN2 is different than that of the GSK3 kinase, in spite of their high sequence homology and similar effects on their substrates. In the Wnt signaling, the phosphorylation of $\beta$-catenin by GSK3 requires a scaffold protein to bring the kinase and the substrate together in a multiprotein complex (Ikeda and others 1998) and a priming phosphorylation (at the C-terminal S/T site of the S/TxxxS/T motif by a CKII kinase) to increase the affinity of $\beta$-catenin for the GSK3 kinase (Liu and others 2002). By contrast, the BIN2-catalyzed BZR l phosphorylation is independent of either a scaffold protein or a priming phosphorylation but requires a direct kinase/substrate docking interaction through a dedicated BIN2-binding motif at the C-terminal end of the substrate (Zhao and others 2002; Peng and Li, unpublished data). Further studies should determine whether the two GSK3mediated signaling pathways share additional mechanistic similarities or whether the plant steroid signaling pathway has additional unique features.

\section{Concluding Remarks and Future Directions}

The rapid progress over the past three years has greatly broadened and deepened our understanding of BR signaling mechanism. The emerging model of BR signal transduction in plants reveals a striking mechanistic similarity to several well-studied signaling pathways in animals. A simple working model for the plant steroid signaling involves the signal perception/initiation by the heterodimerization of BRIl and BAKl at the cell surface, signal relay through yet to be identified component(s) that lead to the inactivation of the BIN2 GSK3 kinase, and subsequent stabilization and nuclear accumulation of BESI and BZRI proteins that regulate an array of BR-responsive genes (Figure 4). However, this is a rather oversimplified linear signaling model and more questions remain to be answered.

With respect to signal perception, it is still not clear whether BR binds to the BRIl/BAKl receptor complex directly or indirectly with the aid of a secreted BR binding/carrier protein that might require a BRS1-mediated proteolysis for maturation. The genetic and biochemical characterization of several putative Arabidopsis steroid-binding proteins mentioned before might provide some useful information to answer this question. It was hypothesized that BR would induce or stabilize BRIl/BAKl heterodimerization, but this process has not yet been directly demonstrated in planta. With the help of several newly developed techniques, such as fluorescence resonance energy transfer (FRET) and protein fragment complementation assay (Rossi and others 2000; Subramaniam and others 2001; Shah and others 2002; Wehrman and others 2002), one could monitor the BRII/BAKl dimerization upon 


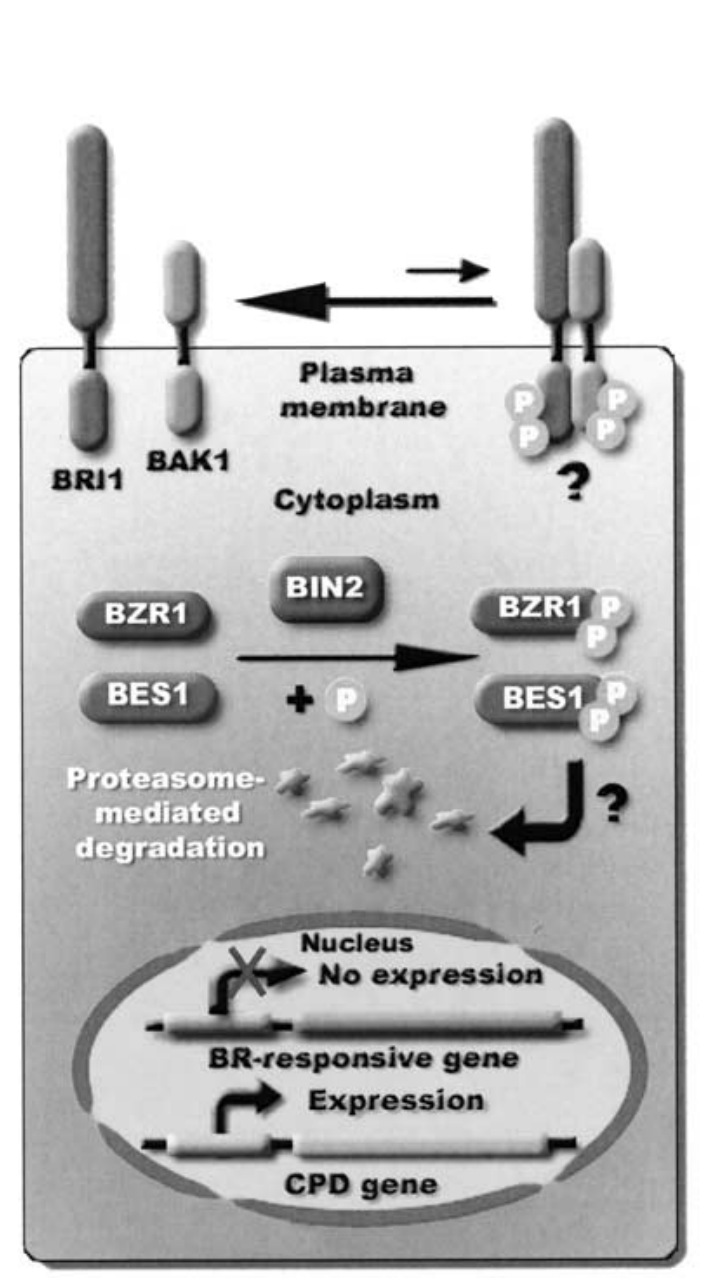

Resting Cell

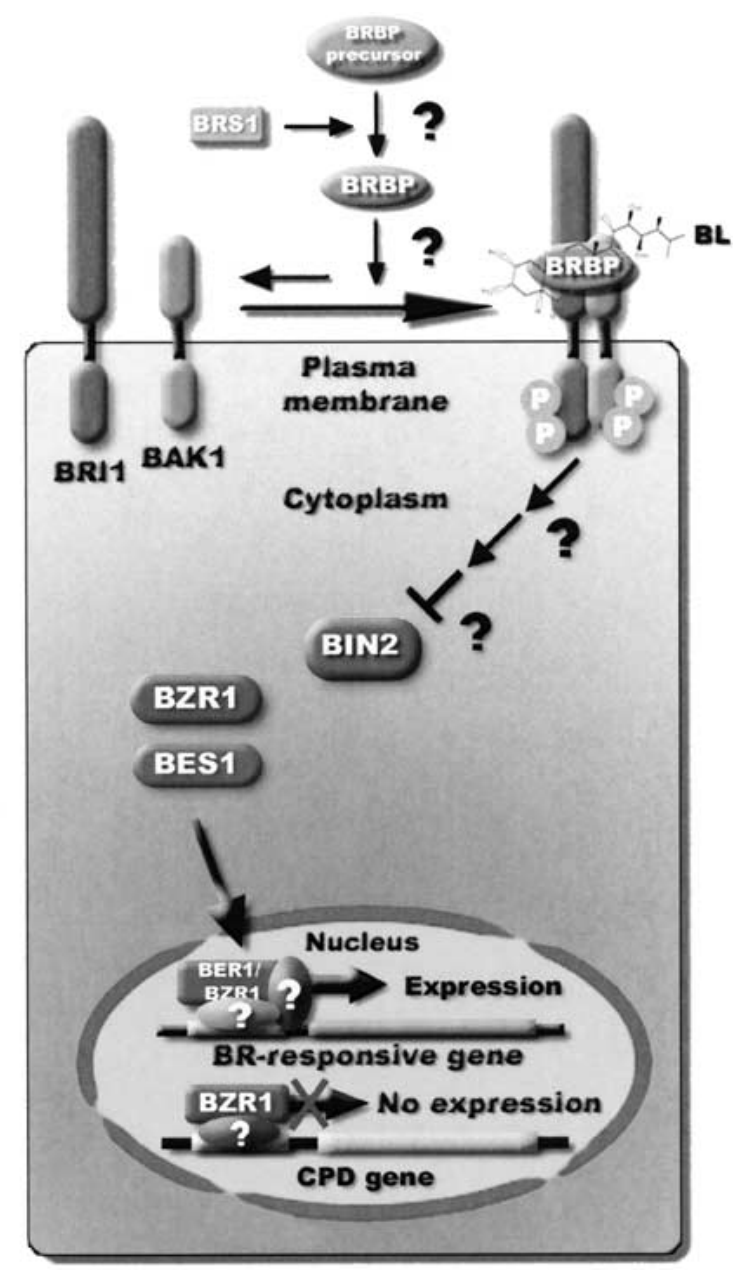

Elongating Cell

Figure 4. A hypothetical BR signaling pathway in Arabidopsis. In the resting cell (left), BRIl and BAKl mainly exist as inactive monomers that are in equilibrium with a tiny pool of BRIl/BAK1 heterodimers. The constitutively active BIN2 phosphorylates BESI and BZRl, earmarking them for proteasome-mediated protein degradation. As a result, no BR signal reaches the nucleus and cell elongation is inhibited. BR binding (right), presumably facilitated by a BR-binding protein (BRBP) that might require BRS1 for proteolytic maturation, shifts the equilibrium to the formation of BRIl/BAKl dimers, thus activating both receptor kinases and transmitting the BR signal into the plant cell. The BR signal is subsequently transduced by yet to be identified signaling components to inhibit the BIN2 kinase activity (see Figure 3C for two possible regulatory mechanisms), allowing the accumulation of both BESI and BZRI in the nucleus to regulate gene expression, possibly through association with other transcriptional factors that contain DNA-binding motifs. Question marks indicate predicted yet uncharacterized components or steps.

BR binding in living plant cells and study the detailed dynamics of the whole dimerization process. Additional studies are also needed to determine whether BAKl is required for BR binding activity or just functions as a signaling component of a BR receptor.

The BRIl/BAKl dimerization is alleged to trigger the autophosphorylation of this receptor kinase pair, which is critical for the activation of the receptor complex and the initiation of downstream signaling events. Thus, identification of the BR-de- pendent autophosphorylation sites on each receptor kinase would help us to understand the mechanism(s) of BR-induced receptor kinase activation. Another important aspect of the receptor kinase is the signaling output, which is essential for transmitting the extracellular BR signal into the cytosol or directly regulating membrane activity to control cell growth. Therefore, identification of putative substrates of BRIl and BAKl using the yeast twohybrid assay and other biochemical approaches, such as purification of a BRIl-containing BR re- 
ceptor complex, would greatly enrich our understanding of the signal relay.

Another intriguing question is how BR perception is regulated throughout plant development. Although BRII seems to be expressed ubiquitously in adult plants, it is still possible that its expression or protein activity is regulated by various endogenous developmental signals. Three BRIl paralogues were found and at least two of them were shown to be functional BR receptors (Yin and others 2002b), but they have more restricted expression profiles compared with BRIl (Yu and $\mathrm{Li}$, unpublished data). Therefore, the competence to respond to BR might be determined by the differential expression patterns of BRIl and its homologues during plant development. The hypothesized BRII/BAKl heterodimerization in mediating BR perception and the fact that Arabidopsis contains 13 BAKl-like proteins add another layer of complexity to the regulation of BR sensitivity. Genetic studies with mutants containing a bakl mutation in combination with mutations in various BAKl homologues or using RNA interference strategy should shed some light on this question.

The signaling mechanism after the activation of the BRII/BAKl receptor kinase pair shares similar logic with that of the Wnt signaling pathway in animals: The signal transmitted from the receptor inactivates a GSK3 kinase, which leads to the dephosphorylation and stabilization of nuclear signaling protein(s), allowing them to accumulate in the nucleus to control gene activities (Figure 4). Like its animal counterparts, BIN2 plays a key role in controlling the amount of the plant steroid signal that can reach the nucleus. A better knowledge of the biochemical mechanism of BIN2 inhibition in response to the plant steroid signal is crucial for a clear understanding of BR signaling. The first step towards this goal is to determine at what level BIN2 is regulated, such as protein stability, subcellular localization, or kinase activity. At the same time, effort should be made to investigate the biochemical consequence of the known bin2 mutations. Although it was reported that the bin2-1 mutation results in a $30 \%$ increase in its kinase activity toward a short peptide substrate, such a moderate increase in the BIN2 activity might not be sufficient to account for the severe dwarf phenotype, which could be phenocopied only by the accumulation of extremely high levels of the wild-type BIN2 transcripts in transgenic plants (Li and Nam 2002). Thus, understanding how these known mutations affect the BIN2 activity could help to unlock the secret of BIN2 regulation in BR signaling. A clear understanding of BIN2 regulation would also re- quire the identification of the missing components that link the activation of the BR receptor and the inhibition of the BIN2 kinase, which could be identified by genetic suppressor/enhancer screen, the yeast two-hybrid method, or purification of a BIN2-containing multiprotein complex.

BES 1 and BZR 1 represent another similar feature between BR and Wnt signaling pathways. Like $\beta$ catenin, both proteins are regulated by similar GSK3-initiated protein degradation processes and are important for controlling nuclear activities (Figure 4). Further investigation of both BESl and BZR I might show whether they share additional similar features with regard to the biochemical mechanisms of their degradation in the cytosol and their actions in the nucleus. In the absence of the Wnt signal, the phosphorylated $\beta$-catenin is recognized by $\beta$-TrCP, an F-box subunit of a ubiquitin ligase complex (SCF) that ubiquitinates and targets $\beta$-catenin for proteasome-mediated proteolysis (Hart and others 1999). It has been shown that the phosphorylated BZR l is degraded by a proteasomemediated process (He and others 2002), but it remains to be determined whether a similar F-box protein is required for the ubiquitination of both BESI and BZRI in BR signaling. In the presence of the Wnt signal, the hypophosphorylated $\beta$-catenin translocates into the nucleus where it interacts with a DNA-binding protein of the TCF family of transcriptional factors to control an array of Wnt target genes (van de Wetering and others 1997; Cavallo and others 1998). It is quite possible that BESI and BZR l might also require DNA-binding proteins to exert their effects on gene regulation because neither protein contains a recognizable DNA-binding motif.

In comparison to the rapid progress in understanding how the plant steroids are transduced to affect gene activity (the genomic effects of BR), the nongenomic aspects of BR have largely been ignored. Although it was known that gene expression is important for many BR-elicited cellular processes, previous studies also indicated that plant steroids could also exert their effects on cell physiology independent of gene regulation. Both the membrane ATPase and vacuolar ATPase were implicated in BRmediated cell growth (Katsumi 1991; Schumacher and others 1999), most likely by facilitating water uptake to generate turgor pressure to drive cell expansion. BR was also known to affect the reorganization of cortical microtubules independent of tubulin gene expression (Mayumi and Shibaoka 1995; Catterou and others 2001), which is essential for determining the direction of cell growth and plant morphogenesis (Williamson 1991; Cyr and 
Palevitz 1995). Further studies are needed to reveal how an activated BR receptor can control the activities of the two different types of ATPases and the nucleation/organization of the microtubules.

The discovery of additional BR signaling components and subsequent detailed genetic and biochemical studies will definitely add more complexity and additional signaling branches to the current simple and linear BR signaling pathway. As an essential plant hormone that plays important roles throughout the plant life cycle, it is also expected that some BR signaling components might also be subject to regulations by other plant hormones and certain endogenous developmental programs. A better understanding of the BR signal transduction pathway will not only contribute significantly to our general knowledge of steroid hormone action but will also provide important insights into the cellular processes governing plant growth and development.

\section{ACKNOWLEDGEMENTS}

The authors would like to thank members of the Li lab for helpful comments on the manuscript. The work done in the authors' laboratory was supported by a grant (GM60519) from the National Institutes of Health.

\section{REFERENCES}

Aberle H, Bauer A, Stappert J, Kispert A, Kemler R. 1997. $\beta$ catenin is a target for the ubiquitin-proteasome pathway. EMBO J 16:3797-3804.

Arabidopsis Genome Initiative2000. Analysis of the genome sequence of the flowering plant Arabidopsis thaliana. Nature 408:796-815.

Aranda A, Pascual A. 2001. Nuclear hormone receptors and gene expression. Physiol Rev 81:1269-1304.

Attisano L, Wrana J. 2002. Signal transduction by the TGF- $\beta$ superfamily. Science 296:1646-1647.

Bhanot P, Brink M, Samos CH, Hsieh JC, Wang Y, Macke JP, Andrew D, Nathans J, Nusse R. 1996. A new member of the frizzled family from Drosophila functions as a Wingless receptor. Nature 382:225-230.

Cato ACB, Nestl A, Mink S. (2002) "Rapid actions of steroid receptors in cellular signaling pathways." Sci STKE 2002/138/ re9..

Catterou M, Dubois F, Schaller H, Aubanelle L, Vilcot B, Sangwan-Norreel BS, Sangwan RS. 2001. Brassinosteroids, microtubules and cell elongation in Arabidopsis thaliana. II. Effects of brassinosteroids on microtubules and cell elongation in the bul1 mutant. Planta 212:673-683.

Cavallo RA, Cox RT, Moline MM, Roose J, Polevoy GA, Clevers H, Peifer M, Bejsovec A. 1998. Drosophila Tcf and Groucho interact to repress Wingless signaling activity. Nature 395:604608.

Choe S, Dilkes BP, Fujioka S, Takatsuto S, Sakurai A, Feldmann KA. 1998. The DWF4 gene of Arabidopsis encodes a cytochrome
P450 that mediates multiple 22alpha-hydroxylation steps in brassinosteroid biosynthesis. Plant Cell 10:231-243.

Choe S, Fujioka S, Noguchi T, Takatsuto S, Yoshida S, Feldmann KA. 2001. Overexpression of DWARF4 in the brassinosteroid biosynthetic pathway results in increased vegetative growth and seed yield in Arabidopsis. Plant J 26:573-582.

Choe S, Schmitz RJ, Fujioka S, Takatsuto S, Lee M-O, Yoshida S, Feldmann KA, Tax FE. 2002. Arabidopsis brassinosteroid-insensitive $d$ warf 12 mutants are semidominant and defective in a glycogen synthase kinase 3 $\beta$-like kinase. Plant Physiol 130: 1506-1515.

Clouse SD, Langford M, McMorris TC. 1996. A brassinosteroidinsensitive mutant in Arabidopsis thaliana exhibits multiple defects in growth and development. Plant Physiol 111:671678.

Clouse SD, Sasse JM. 1998. Brassinosteroids: essential regulators of plant growth and development. Annu Rev Plant Physiol Plant Mol Biol 49:427-451.

Clouse SD. 2002a. Brassinosteroid signal transduction: clarifying the pathway from ligand perception to gene expression. Mol Cell 10:973-982.

Clouse SD. 2002b. Brassinosteroid signaling: novel downstream components emerge. Curr Biol 12:R485-R487.

Cross DA, Alessi DR, Cohen P, Andjelkovich M, Hemmings BA. 1995. Inhibition of glycogen synthase kinase-3 by insulin mediated by protein kinase B. Nature 378:785-789.

Cyr RJ, Palevitz BA. 1995. Organization of cortical microtubules in plant cells. Curr Opin Cell Biol 7:65-71.

Dajani R, Fraser E, Roe SM, Young N, Good V, Dale TC, Pearl LH. 2001. Crystal structure of glycogen synthase kinase $3 \beta$ : structural basis for phosphate-primed substrate specificity and autoinhibition. Cell 105:721-723.

Dominguez I, Green JBA. 2001. Missing links in GSK3 regulation. Dev Biol 235:303-313.

Frame S, Cohen P. 2001. GSK3 takes centre stage more than 20 years after its discovery. Biochem 1359:1-16.

Friedrichsen DM, Joazeiro CA, Li J, Hunter T, Chory J. 2000. Brassinosteroid-insensitive- 1 is a ubiquitously expressed leucine-rich repeat receptor serine/threonine kinase. Plant Physiol 123:1247-1256.

Fujioka S, Yokota T. 2003. Biosynthesis and metabolism of brassinosteroids. Annu Rev Plant Biol 54:137-164.

Grazzini E, Guillon G, Mouillac B, Zingg HH. 1998. Inhibition of oxytocin receptor function by direct binding of progesterone. Nature 392:509-512.

Hammes SR. 2003. The further redefining of steroid-mediated signaling. Proc Natl Acad Sci USA 100:2168-3170.

Hart M, Concordet JP, Lassot I, Albert I, del los Santos R, Durand H, Perret C, Rubinfeld B, Margottin F, Benarous R, Polakis P. 1999. The F-box protein $\beta$-TrCP associates with phosphorylated $\beta$-catenin and regulates it activity in the cell. Curr Biol 9:207210.

He J-X, Gendron JM, Yang Y, Li J, Wang Z-Y. 2002. The GS3-like kinase BIN2 phosphorylates and destabilizes BZR1, a positive regulator of the brassinosteroid signaling pathway in Arabidopsis. Proc Natl Acad Sci USA 99:10185-10190.

He Z, Wang Z-Y, Li J, Zhu Q, Lamb C, Ronald P, Chory J. 2000. Perception of brassinosteroids by the extracellular domain of the receptor kinase BRIl. Science 288:2360-2363.

Hecht A, Kemler R. 2000. Curbing the nuclear activities of $\beta$ catenin. Control over Wnt target gene expression. EMBO Rep $1: 24-28$.

Hecht V, Vielle-Calzada JP, Hartog MV, Schmidt ED, Boutilier K, Grossniklaus U, de Vries SC. 2001. The Arabidopsis SOMATIC EMBRYOGENESIS RECEPTOR KINASE 1 gene is expressed in 
developing ovules and embryos and enhances embryogenic competence in culture. Plant Physiol 127:803-816.

Hong Z, Ueguchi-Tanaka M, Shimizu-Sato S, Inukai Y, Fujioka S, Shimada Y, Takatsuto S, Agetsuma M, Yoshida S, Watanabe Y, Uozu S, Kitano H, Ashikari M, Matsuoka M. 2002. Loss-offunction of a rice brassinosteroid biosynthetic enzyme, C-6 oxidase, prevents the organized arrangement and polar elongation of cells in the leaves and stem. Plant J 32:495-508.

Ikeda S, Kishida S, Yamamoto H, Murai H, Koyama S, Kikuchi A. 1998. Axin, a negative regulator of the Wnt signaling pathway, forms a complex with GSK-3 $\beta$ and $\beta$-catenin and promotes GSK-3 $\beta$-dependent phosphorylation of $\beta$-catenin. EMBO J 17:1371-1384.

Katsumi M. 1991. Physiological modes of brassinolide action in cucumber hypocotyls growth. In: Cutler HG, Yokota T, Adam G Eds. Brassinosteroids: Chemistry, Bioactivity, and Application. ACS Symp Ser 474. Washington, DC: American Chemical Society. pp 246-254.

Kauschmann A, Jessop A, Koncz C, Szekeres M, Willmitzer L, Altmann T. 1996. Genetic evidence for an essential role for brassinosteroids in plant development. Plant J 9:701-713.

Koka CV, Cerny RE, Gardner RG, Noguchi T, Fujioka S, Takatsuto S, Yoshida S, Clouse SD. 2000. A putative role for the tomato genes DUMPY and CURL-3 in brassinosteroid biosynthesis and response. Plant Physiol 122:85-98.

Li J, Chory J. 1997. A putative leucine-rich repeat receptor kinase involved in brassinosteroid signal transduction. Cell 90:929938.

Li J, Lease KA, Tax FE, Walker JC. 200la. BRS1, a serine carboxypeptidase, regulates BRIl signaling in Arabidopsis thaliana. Proc Natl Acad Sci USA 2001 98:5946-5921.

Li J, Nagpal P, Vitart V, McMorris TC, Chory J. 1996. A role for brassinosteroids in light-dependent development of Arabidopsis. Science 272:398-401

Li J, Nam KH, Vafeados D, Chory J. 2001b. BIN2, a new brassinosteroid-insensitive locus in Arabidopsis. Plant Physiol 127:1422.

Li J, Nam KH. 2002. Regulation of brassinosteroid signaling by a GSK3/SHAGGY-like kinase. Science 295:1299-1301.

Li J, Wen J, Lease KA, Doke JT, Tax FE, Walker JC. 2002. BAK1, an Arabidopsis LRR receptor-like protein kinase, interacts with BRIl and modulates brassinosteroid signaling. Cell 110:213222.

Li J. 2003. Brassinosteroids signal through two receptor kinases. Curr Opin Plant Biol. 6:494-499.

Liu C, Li Y, Semenov M, Han C, Baeg G-H, Tan Y, Zhang Z, Lin X, He X. 2002. Control of $\beta$-catenin phosphorylation/degradation by a dual-kinase mechanism. Cell 108:837-847.

Losel R, Wehling M. 2003. Nongenomic actions of steroid hormones. Nat Rev Mol Cell Biol 4:46-56.

Markovic-Housley Z, Degano M, Lamba D, von RoepenackLahaye E, Clemens S, Susani M, Ferreira F, Scheiner O, Breiteneder H. 2003. Crystal structure of a hypoallergenic isoform of the major birch pollen allergen Bet $\mathrm{v} 1$ and its likely biological function as a plant steroid carrier. J Mol Biol 325:123133.

Mathur J, Molnar G, Fujioka S, Takatsuto S, Sakurai A, Yokota T, Adam G, Voigt B, Nagy F, Maas C, Schell J, Koncz C, Szekeres M. 1998. Transcription of the Arabidopsis CPD gene, encoding a steroidogenic cytochrome P450, is negatively controlled by brassinosteroids. Plant J 14:593-602.

Mayumi K, Shibaoka H. 1995. A possible double role for brassinolide in the reorientation of cortical microtubules in the epidermal cells of Azuki bean epicotyls. Plant Cell Physiol 36:173181.
Meggio F, Pinna LA. 2003. One-thousand-and-one substrates of protein kinase CK2. FASEB J 17:349-368.

Montoya T, Nomura T, Farrar K, Kaneta T, Yokota T, Bishop GJ. 2002. Cloning the tomato Curl3 gene highlights the putative dual role of the leucine-rich repeat receptor kinase tBRII/ SR160 in plant steroid hormone and peptide hormone signaling. Plant Cell 14:3163-3176.

Mori M, Nomura T, Ooka H, Ishizaka M, Yokota T, Sugimoto K, Okabe K, Kajiwara H, Satoh K, Yamamoto K, Hirochika H, Kikuchi S. 2002. Isolation and characterization of a rice dwarf mutant with a defect in brassinosteroid biosynthesis. Plant Physiol 130:1152-1161.

Nam KH, Li J. 2002. BRI1/BAK1, a receptor kinase pair mediating brassinosteroid signaling. Cell 110:203-212.

Noguchi T, Fujioka S, Choe S, Takatsuto S, Yoshida S, Yuan H, Feldmann K, Tax F. 1999. Brassinosteroid-insensitive dwarf mutants of Arabidopsis accumulate brassinosteroids. Plant Physiol 121:743-752.

Nomura T, Bishop GJ, Reid JB, Yokota T. 2001. Identification of the pea brassinosteroid receptor gene LKA as a BRIl homolog. 17th International Conference on Plant Growth Substances. Brno, Czech Republic, Abstract No. 261.

Nomura T, Kitasaka Y, Takatsuto S, Reid JB, Fukami M, Yokota T. 1999. Brassinosteroid/Sterol synthesis and plant growth as affected by $l k a$ and $l k b$ mutations of pea. Plant Physiol 119:15171526.

Nomura T, Nakayama M, Reid JB, Takeuchi Y, Yokota T. 1997. Blockage of brassinosteroid biosynthesis and sensitivity causes dwarfism in garden pea. Plant Physiol 113:31-37.

Nusse R. 1997. A versatile transcriptional effector of Wingless signaling. Cell 89:321-323.

Oh MH, Ray WK, Huber SC, Asara JM, Gage DA, Clouse SD. 2000. Recombinant brassinosteroid-insensitive 1 receptor-like kinase autophosphorylates on serine and threonine residues and phosphorylates a conserved peptide motif in vitro. Plant Physiol 124:751-766.

Peifer M, Wieschaus E. 1990. The segment polarity gene armadillo encodes a functionally modular protein that is the Drosophila homolog of human plakoglobin. Cell 63:1167-1176.

Perez-Perez J, Ponce MR, Micol JL. 2002. The UCU1 Arabidopsis gene encodes a SHAGGY/GSK3-like kinase required for cell expansion along the proximodistal axis. Dev Biol 242:161173.

Rosner W, Hryb DJ, Khan MS, Nakhla AM, Romas NA. 1999. Sex hormone-binding globulin mediates steroid hormone signal transduction at the plasma membrane. J Steroid Biochem Mol Biol 69:481-485.

Rossi FMV, Blakely BT, Blau HM. 2000. Interaction blues: protein interactions monitored in live mammalian cells by $\beta$-galactosidase complementation. Trends Cell Biol 10:119-122.

Ryves WJ, Harwood AJ. 2002. Lithium inhibits glycogen synthase kinase- 3 by competition for magnesium. Biochem Biophys Res Commun 280:720-725.

Scheer J, Ryan Jr CA. 2002. The systemin receptor SR160 from Lycopersicon peruvianum is a member of the LRR receptor kinase family. Proc Natl Acad Sci USA 99:9585-9590.

Schlessinger J. 2000. Cell signaling by receptor tyrosine kinase. Cell 103:211-225.

Schultz L, Kerckhoffs LH, Klahre U, Yokota T, Reid JB. 2001. Molecular characterization of the brassinosteroid-deficient $l k b$ mutant in pea. Plant Mol Biol 47:491-498.

Schumacher K, Vafeados D, McCarthy M, Sze H, Wilkins T, Chory J. 1999. The Arabidopsis det3 mutant reveals a central role for the vacuolar $\mathrm{H}(+)$-ATPase in plant growth and development. Genes Dev 13:3259-3270. 
Shah K, Russinova E, Gadella Jr TWJ, Willemse J, de Vries SC. 2002. The Arabidopsis kinase-associated protein phosphatase controls internalization of the somatic embryogenesis receptor kinase 1. Genes Dev 16:1707-1720.

Shaul PW. 2002. Regulation of endothelial nitric oxide synthase: location, location, location. Annu Rev Physiol 64:749-774.

Shiu SH, Bleecker AB. 2001. Receptor-like kinases from Arabidopsis form a monophyletic gene family related to animal receptor kinases. Proc Natl Acad Sci USA 98:10763-10768.

Song WY, Wang GL, Chen LL, Kim HS, Pi LY, Holsten T, Gardner J, Wang B, Zhai WX, Zhu LH, Fauquet C, Ronald P. 1995. A receptor kinase-like protein encoded by the rice disease resistance gene Xa21. Science 270:1804-1806.

Subramaniam R, Desveaux D, Spickler C, Michnick SW, Brisson N. 2001. Direct visualization of protein interactions in plant cells. Nat Biotechnol 19:769-772.

Szekeres M, Nemeth K, Koncz-Kalman Z, Mathur J, Kauschmann A, Altmann T, Redei GP, Nagy F, Schell J, Koncz C. 1996. Brassinosteroids rescue the deficiency of CYP90, a cytochrome P450, controlling cell elongation and de-etiolation in Arabidopsis. Cell 85:171-182.

Szekeres M. 2003. Brassinosteroid and systemin: two hormones perceived by the same receptor. Trends Plant Sci 8:102104.

ter Haar E, Coll JT, Austen DA, Hsiao H-M, Swenson L, Jain J. 2001. Structure of GSK-3 $\beta$ reveals a primed phosphorylation mechanism. Nat Struct Biol 8:593-596.

van de Wetering $M$, Cavallo R, Dooijes D, van Beest M, van Es J, Loureiro J, Ypma A, Hursh D, Jones T, Bejsovec A, Peifer M, Mortin M, Clevers H. 1997. Armadillo coactivates transcription driven by the product of the Drosophila segment polarity gene dTCF. Cell 88:789-799.

Wang Z-Y, Nakano T, Gendron J, He J, Chen M, Vafeados D, Yang Y, Fujioka S, Yoshida S, Asami T, Chory J. 2002. Nuclearlocalized BZRl mediates brassinosteroid-induced growth and feedback suppression of brassinosteroid biosynthesis. Dev Cell 2:505-513.

Wang Z-Y, Seto H, Fujioka S, Yoshida S, Chory J. 2001. BRIl is a critical component of a plasma-membrane receptor for plant steroids. Nature 410:380-383.

Wehrman T, Kleaveland B, Her J-H, Balint RF, Blau HM. 2002. Protein-protein interactions monitored in mammalian cells via complementation of $\beta$-lactamase enzyme fragments. Proc Natl Acad Sci USA 99:3469-3474.

Williamson RE. 1991. Orientation of cortical microtubules in interphase plant cells. Int Rev Cytol 129:135-206.

Yamamuro C, Ihara Y, Wu X, Noguchi T, Fujioka S, Takatsuto S, Ashikari M, Kitano H, Matsuoka M. 2000. Loss of function of a rice brassinosteroid insensitive 1 homolog prevents internode elongation and bending of the lamina joint. Plant Cell 12:15911606.

Yin Y, Wang Z-Y, Mora-Garcia S, Li J, Yoshida S, Asami T, Chory J. 2002a. BESl accumulates in the nucleus in response to brassinosteroids to regulate gene expression and promote stem elongation. Cell 109:181-191.

Yin Y, Wu D, Chory J. 2002b. Plant receptor kinases: systemin receptor identified. Proc Natl Acad Sci USA 99:9090-9092.

Zhao J, Peng P, Schmitz RJ, Decker AD, Tax FE, Li J. 2002. Two putative BIN2 substrates are nuclear components of brassinosteroid signaling. Plant Physiol 130:1221-1229. 